\title{
Young's Social Connection Model and Corporate Responsibility
}

\author{
Robert Phillips ${ }^{1}$ (D) J Judith Schrempf-Stirling ${ }^{2}$
}

Received: 2 March 2021 /Accepted: 6 April 2021 / Published online: 4 May 2021

(C) The Author(s) 2021

\begin{abstract}
Recent structural innovations in global commerce present difficult challenges for legacy understandings of responsibility. The rise of outsourcing, sub-contracting, and mobile app-based platforms have dramatically restructured relationships between and among economic actors. Though not entirely new, the remarkable rise in the prevalence of these "not-quite-arm's-length" relationships present difficulties for conceptions of responsibility based on interrogating the past for specifiable actions by blameworthy actors. Iris Marion Young invites investigation of a "social connection model of responsibility" (SCMR) that is, in many ways, better suited to this new commercial reality. Scholars working to understand corporate responsibility have invoked Young's model to some good effect, though often superficially and uncritically. In this paper, we look closely at Young's social connection model and its potential for helping us understand corporate responsibility in a radically networked world.
\end{abstract}

Keywords Corporate responsibility $\cdot$ Social connection model $\cdot$ Marion Young

\section{Introduction}

Recent structural innovations in global commerce present difficult challenges for legacy understandings of responsibility. The rise of outsourcing, sub-contracting, and mobile appbased platforms have dramatically restructured relationships between and among economic actors. Though not entirely new, the remarkable rise in the prevalence of these "not-quite-

Robert Phillips

rphillips@schulich.yorku.ca

Judith Schrempf-Stirling

judith.schrempf-stirling@unige.ch

1 Schulich School of Business, York University, 4700 Keele Street, Toronto, Ontario M3J 1P3, Canada

2 Institute of Management, Geneva School of Economics and Management, University of Geneva, 40 bd du Pont d'Arve, CH - 1211, Geneva 4, Switzerland 
arm's-length" relationships present difficulties for conceptions of responsibility based on interrogating the past for specifiable actions by blameworthy actors, such as the liability model of responsibility (LMR). The LMR is characterized by just and stable social structures, a backward-looking perspective, and the identification of a culpable actor leading to the absolution of other candidates for responsibility.

In contrast to LMR, Iris Marion Young (2011) invites investigation of a "social connection model of responsibility" (SCMR) that is, in many ways, better suited to this new commercial reality. Young's SCMR focuses on injustices that are the result of structural processes. Young's social connection responsibility (SCR) primarily involves "an evaluation of how the institutions of a society work together to produce outcomes that support or minimize the threat of domination, and support or minimize everyone's opportunities to develop and exercise capacities for living a good life as they define it" (Young 2003a, p. 7).

Young's early work on structural injustice (Young 2006; cf. 2011, p. 8) was motivated by her concerns with "global labor justice," but there is much more to say about these structures and the role SCMR can play - particularly regarding the organization of commerce. SCMR has gained increasing attention amongst scholars in the business ethics literature (Wickert 2016; Schrempf 2012; Maak 2009; Scherer and Palazzo 2011). What is missing in these discussions, though, is a systematic internal critique of SCMR (for an exception see Hahn 2009) and its potential to inform business responsibilities. Generally, authors either render refutations en route to defending their own preferred position or are uncritically credulous about the parameters of a model similarly en route to defending their preferred position.

Here we (1) critically reflect on SCMR, (2) clarify its relationship to the standard (liability) model of assigning responsibility, and (3) illustrate the relevance and limits of SCMR by applying it to the emerging scholarship on business and human rights. We seek to better understand the contours of the division of conceptual labor between SCMR and LMR and the implications of these contours for organizational ethics. For any given occurrence of structural injustice, how are we to know which model is most appropriate to inform our understanding of managerial responsibility? It is also important to account for movement between the two models. Closer attention to SCMR's defining and distinctive characteristics not only provides some responses to the model's critics, but more importantly, help guide the model's (mis)use in examining questions of the role of business and managers in addressing structural injustice.

The paper is organized as follows. First, we summarize the LMR and Young's conceptualization of an alternative model of responsibility, SCMR. Second, we provide an overview of scholars applying and criticizing SCMR within business ethics scholarship. We then present our internal critique of SCMR and carve out important nuances in Young's model to clarify the relationship between SCMR and LMR. We then consider the application of the two models to questions of business and human rights and conclude.

\section{Liability Model of Responsibility}

The contours of the liability approach are recognizable from the law. Concepts such as guilt, blame, isolatable and identifiable actors and actions, and restitution are standard elements of the received understanding of responsibility. As a preliminary to explaining SCMR, we will examine more closely some of the features of the liability approach as highlighted by Young (2004). Specifically, the LMR 
- Assumes that actions occur within the context of generally just social structures,

- Looks to the past to identify actions, actors, and the magnitude of harm caused as well as to establish form and magnitude of restitution, and

- Identifies specific responsible actors and, in so doing, absolves others from blame and obligations to compensate those harmed.

Just Social Structures Social structure refers to the background conditions, assumptions, norms, laws, policies, expectations, beliefs, etc. that help us make sense of interactions with others. Most of these structures are generally taken-for-granted and are mutually reinforcing of, or at least mutually adapted to, the other structures. Indeed, it is only through some measure of coherence and effectiveness that stable and recognizable institutions arise and self-reinforce.

The number of these structures, sub-structures, institutions, etc. is limited only by our imaginative capacity to identify them and their effects. Free market capitalism, the rule of law, religion, the family, and all of the -ocracies and -archies (democracy, theocracy, aristocracy, monarchy, oligarchy, patriarchy, etc.) have identifiable and predictable "side-effects" on the decisions, actions, and outcomes for those subject to them. Every structure necessarily privileges certain capacities among those subject to them (e.g., family background, gender or sexuality, superannuation, intellect, physical strength, creativity, persistence, aggression, and loyalty) while systematically disadvantaging others.

Most relevant for our purposes, such systems, structures, and institutions are critically examined (save philosophers and social critics) only when something about the system is found to be inconsistent with other parts of the system or have otherwise become unbearably dysfunctional. Indeed, even faced with apparently anomalous outcomes, we would more frequently look for ways the system malfunctioned rather than entertain the possibility that this "anomaly" is an inherent and predictable ("side-")effect of the system.

Responsibility assessments under LMR are made without evaluation of this system itself. It is generally assumed, even taken-for-granted, that the background conditions within which actions occur and consequences are judged is itself just. Particularly concerning legal responsibility, this is appropriate in light of the value placed on stability and predictability in legal systems.

What counts as normal system function is generally tied to some moment in time. This moment is, itself, presumed to have been an expression of a just background structure until a violation is noticed. Assessing responsibility, blame and recompense for harm must be framed in terms of deviations from this status quo ante. In other words, liability reasoning is essentially backward looking.

Backward Looking Liability seeks to redress unjust actions from some time in the past (Fletcher 1999). Blame, guilt, and compensation all require consideration of what happened and by whose hand. Punishment requires specification of a blameworthy past action; restitution seeks to return victims, as far as practicable, to their pre-violation situation. Though there is also some concern with rehabilitation and deterrence, the ingredients that inform attributions of liability-based responsibility look to the past. The LMR looks to the past as the baseline against which current behavior is measured. According to the LMR, actors are responsible for their actions - or possibly inactions - within a system that frames and organizes these decisions and their outcomes. The LMR seeks to identify - and attach fault to - specific actors. Moreover, when these specific vessels for fault are identified, the search for other blame candidates ceases. That is, liability-based responsibility is isolating. 
Isolating According to Young, LMR seeks to single out particular actors for blame and, perhaps, compensation or redress. Moreover, having identified the responsible actors, all others are, "by implication," absolved. Others may have been somehow associated with, or proximate to, or able to stop the harm, but they are not responsible according to the liability model. Indeed, these non-liable actors may have benefitted from the harm, acted within the system that generated the harms, and/or had the capacity or resources to remediate. Even so, they still have no liability-based responsibility. If the actors in question are behaving within the norms, rules, and laws of the relevant institutions and structures, they are not liable for blame, guilt, or punishment. ${ }^{1}$

Though not part of Young's elaboration, we argue that the LMR must not only isolate the responsible actor, but also the specific blameworthy act. Liability-based responsibilities point to specific instances of wrongdoing. Merely contributing to - or benefitting from - a harmful outcome is insufficient for holding an actor responsible. The act must, absent some other source of expectation (e.g., strict liability), be identifiable as the entire cause of the harm. Acts that do not meet this causal standard are generally not candidates for blame under the LMR.

Having sketched (or, perhaps, caricatured) the elements of responsibility generally characteristic of our received (liability-based) theories, we can now proceed to outline the social connection-based alternative.

\section{Social Connection Model of Responsibility}

For Young, the social connection model involves four key features (Young 2011, pp. 104-13):

- Structure as Subject

- Forward-Looking

- Not Isolating/Essentially Shared

- Discharged Only Through Collective Action

Structure as Subject Young's SCMR focuses on injustices that are the result of structural processes. Structure refers to institutional rules, norms, and routines in which individual behavior is embedded. These structures and their context limit and enable individuals to act. Young writes, "If we wish to understand and criticize the way that many individuals and groups face too limited and unsavory sets of options, then we need an account of large-scale

\footnotetext{
${ }^{1}$ We should pause here to point out that Young's description of the liability model of responsibility is a bit of a caricature. It most closely describes Western, liberal democratic systems of legal responsibility and, though deeply scholarly, many of her characterizations may be objectionable to those who believe the liability model is, when applied reflectively, more than flexible enough to accommodate the challenges of systemic injustice. Our purpose here is not, in general, to contrast Young's characterization of prevailing concepts of responsibility. On balance, we find her descriptions well-evidenced and consistent with our own understandings. With this said, we will spare a critical word about exculpation in the LMR. Of those writing about SCMR (more on this below), most simply take Young at her word that assessments of LMR not only isolate specific (possibly corporate) actors, but also absolve all others. This leap of logic is among the less-thoroughly justified in her characterization of the LMR. Indeed, the passage most often cited in reference to exculpation by isolation is, "In general, the liability model of responsibility seeks to mark out and isolate those responsible, thereby distinguishing them from others, who by implication are not responsible.” (Young 2011, p. 105; cf. Young 2004, p. 377 and 2006, p. 119).
} 
systemic outcomes of the operations of many institutions and practices that constrain some people at the same time that they enable others" (Young 2003a, p. 4).

Social structures are dynamic, and exist through the actions and inactions of individuals. The focus on individual actions is only of secondary importance in Young's model as these individual actions are limited and enabled by the structures. Hence, the ultimate focus in SCMR lies on structural injustices and thereby calls the very justness of the background conditions themselves into question. Young writes, "When we judge the structural injustice exists, we are saying precisely that at least some of the normal and accepted background conditions of action are not morally acceptable. Most of us contribute to a greater or lesser degree to the production and reproduction of structural injustice precisely because we follow the accepted and expected rules and conventions of the communities and institutions in which we act" (2011, p. 107). Far from being taken-for-granted as just or fair, the background conditions and their harmful effects on those living within these structures are the catalyst for, and object of, critical examination.

It is generally recognized that some people win the natural lottery at birth through unearned endowments including, but not limited to, gender, nationality, social standing, (dis)abilities, etc. These initial endowments determine in no small degree the likely outcomes for these in utero dice-rollers. Importantly, however, the background conditions play a key role in which endowments count as beneficial or harmful. Gender is a source of distinction around the world and throughout history, but the extent to which it is a source of structural injustice varies greatly between societies with differing social structures. The fact that there exist such differences suggests that these structures can be altered.

These differences even dictate what counts as "moral luck". Luck implies that there was nothing that could have been done differently to affect the outcomes. If one is born with a particular non-advantageous endowment within a given social structure, it is a matter of force majeure. It can perhaps be compensated for, but not avoided. "Structure" has a sense of permanence which can tend toward reification. ${ }^{2}$ For a theory designed explicitly to address flaws in a social structure, this mutability cannot be overemphasized. Emphasis on structure reminds us that what counts as (un)lucky is not itself a force of nature, immutable law, or act of god.

Relying on Anderson's (1999) critique of luck egalitarianism, Young argues that it is inadequate to simply recognize the structural injustice and attempt to compensate those subject to its mercies. There is a pitying tendency that infects both beneficiary and victim that could be reduced by altering the structure that created the need for compensation in the first place. According to Young, the recognition of injustice implicit in the compensation should itself motivates its alteration (Young 2011, p. 34). It is vital, then, that we recognize the central role of structure to understanding justice, but also that we recognize the flexibility of this structure and look for approaches that address its symptoms and, where possible, bend it toward justice.

SCMR considers social structure itself as a mutable part of human interaction. The structure is a human creation that privileges certain traits, abilities, tendencies, and actions over others. Over time, these privileges themselves become taken for granted, even natural. Actors lacking the prized capabilities do not do as well within the system, yet the disparities are seen as natural as well. SCMR seeks a direct examination of the system and its prized capabilities. Individual actors and agency remain important for SCMR (though perhaps less so than in the LMR as elaborated below), but responsibility is extended to encompass actions that are normal within the jointly-

${ }^{2}$ Young devotes several pages (2011p. 154ff) to the dangers of reification - largely in its use as a responsibility denial mechanism (cf., Phillips 2010). 
enacted system. People are responsible not only for harm they individually and directly cause, but for directly addressing injustices arising from the normal system function.

Forward-Looking One defining element of Young's SCMR is that it is "more forwardlooking than backward-looking" (Young 2011, p. 108). SCMR emphasizes finding shared solutions over finding somewhere to lay blame. This element of Young's thinking has received a great deal of attention. Indeed, in an otherwise laudatory Foreword to Young's posthumously published statement of her model, Nussbaum's (2011) main points of objection are with this emphasis on the future rather than the past. Young's reasoning - as well as Nussbaum's critique - frame this element of SCMR well. Five reasons underlying the forward-looking perspective are:

- Focusing on blame distracts from thought and action directed at addressing the injustice,

- Blaming one actor or group tends to give a sense of exoneration to others,

- Focusing on blame distracts from (even reinforces) the background conditions,

- Blaming puts people on the defensive and reduces the chances of productive cooperation, and

- Guilt focuses attention inward rather than toward those harmed and other potential contributors to amelioration.

This emphasis on distraction and the psychology of blame and guilt leads Nussbaum to question the necessity of Young's claims. Many of her objections are of the "may be, but need not or should not be" variety. The actors may be distracted or feel a sense of exoneration or defensiveness or self-absorption, but they need not. Of course, Nussbaum's concerns about logical necessity are worth considering, but a more pressing question is whether we take human tendencies as we find them or as they could be or as we wish they were. Both aspirational and behavioral models have a role to play in moral discourse, but it is fair to say that behavioral models are having a moment - including in philosophy (Appiah 2008; Greene 2013). For example, Darby and Branscombe (2014) argue that the psychology of responsibility attributions gives reason to believe that looking forward may result in better shared solutions. The question becomes one of balancing aspiration and shorter-term impact.

For SCMR, it is "always now" (Young 2011, p. 92). Young claims that SCMR is "more" forward- than backward-looking because there remains a distinctive role for the past. That role is not to blame, find fault, or assess punishments and restitution. The past provides only the causal evidence that will inform forward-looking actors about the likely outcomes of a given set of alternatives. Scrupulously maintaining focus on the future is difficult and may, to many, leave out important considerations. This point has implications for the extent and duration of social connection responsibilities. Are these responsibilities resolvable without taking leave of the entire system? Can social connection responsibilities be "discharged" at all short of utopia? If not, is this a criticism or does it make the approach itself utopian? More on these questions below.

Not Isolating/ Essentially Shared Social connection responsibility is, in Young's term, essentially a shared responsibility. Though she does not elaborate on her interpretation of "essence", she uses the term "essentially" sparingly, but consistently, throughout her elaboration and description. To be essentially shared means that the responsibility cannot be meaningfully isolated and applied to specific actors for specific harms - harms that are themselves at a "terminus." We can identify actors and the continuing injustice their actions manifest, but each individual actor's role in the injustice is often negligible and/or within the accepted norms 
of the system under scrutiny. Social connection responsibility is an essentially shared responsibility due to the nature of harm, the diffusion and normalcy of actors' contributions to the harm, and the inability of actors to individually and personally mitigate the injustice. As Young writes, "My responsibility is essentially shared with others because the harms are produced by many of us acting together within accepted institutions and practices, and because it is not possible for any of us to identify just what in our actions results in which aspects of the injustice that particular individual suffer" (Young 2011, p. 110).

Importantly, actors bear SCR precisely when they are acting within the accepted rules and norms of society. If the actors or actions in question landed outside these normative boundaries, they would be liable and blameworthy under the prevailing LMR (more on this division of conceptual labor as well as the dynamics of moving between LMR and SCMR below). Even when unaware of the injustice or their role in its creation and reinforcement - indeed, even those harmed by this selfsame structural injustice - may bear responsibility. Again Young:

In principal, moreover, structural injustice may be ongoing even when some of the participating actors have done nothing that existing practices of criminal, legal, or moral blame or fault finding would identify as wrong. Those who participate by their actions in producing and reproducing structural injustice are usually minding their own business and acting within accepted norms and rules (Young 2011, p. 106).

Young acknowledges a debt to Larry May's work on Sharing Responsibility (May 1992). In particular, May's distinction between collective responsibility and shared responsibility is relevant for our purposes. Collective responsibility applies when the group in question is able to act as a unit (cf. Hess 2014). A nation's responsibility for wartime actions has been a topic of deep and extensive scrutiny regarding collective responsibility including consideration of whether and how collective responsibility cascades among the individuals within the collective. According to some, individuals within collectives are deemed not responsible for the actions of the collective.

On Young's account, shared responsibility is different. Though applied to members of a group it is nevertheless a personal responsibility that arises due to normal participation in the on-going structures that culminate in injustice. Also, though May uses the term "shared" responsibility, Young sees his motivating cases as more exemplary of the liability model against which she seeks to juxtapose SCMR. Young writes, “... [t]he wrongs for which May seeks to assign responsibility fit a liability model more than not. He presents them as wrongs that deviate from a baseline and have reached a terminus. Thus, May's application of the idea of shared responsibility is more backward-looking than forward-looking." (2011, p. 111). She goes on, "the wrongs with which May is concerned have identifiable perpetrators, who are guilty; the idea of shared responsibility applies to others who are not guilty of the wrongs but have attitudes similar to the perpetrators that help create a climate that allows or encourages harm" (2011, p. 111). ${ }^{3}$

Importantly for Young, finding an actor as responsible - either by the standards of liability or by social connection - does not serve to exculpate others. She writes, "Where there are structural injustices, finding that some people are guilty of perpetrating specific wrongful actions does not

\footnotetext{
${ }^{3}$ Though not explicitly addressed by Young, there is nothing precluding an actor from being party to a collective responsibility (e.g., as a member of an organization that has caused harm) as well as bearing additional shared responsibility - personally and individually - for their role in a system that produces and reproduces injustice.
} 
absolve others whose actions contribute to the outcomes from bearing responsibility in a different way" (Young 2011, p. 106). Because social connection responsibility is essentially shared, there is plenty of responsibility to go around. All who sustain the policies and institutions that manifest structural injustice remain responsible. Indeed, even where specific wrongful acts within the system can be isolated and liability, blame, punishment, and compensation can be assessed, social connection responsibility remains undiminished. For Young, this essentially shared nature leads her to maintain that responsibility for structural injustice can only be discharged (if at all) through collective action. It is to this that we now turn.

Discharged Only through Collective Action Following from the descriptor "essentially shared," SCR can only be addressed in concert with others according to Young. She claims, "Most of us are objectively constrained by the rules, norms, and material effects of structural processes when we try to act alone. These processes can be altered only if many actors from diverse positions within the social structure work together to intervene in them to try to produce other outcomes" (2011, p. 111). Young's focus on structural injustices leads her to surmise that the ultimate responsibility for structural injustices can only be met by collective action. Regarding the former term (i.e., collective) Young writes:

For most such injustices, the goal is to change structural processes by reforming institutions or creating new ones that will better regulate the process to prevent harmful outcomes. Thus a final consideration in reasoning about where a person might put her practical energies in taking political responsibility involves coordination with others to achieve such change. Just as a person can make almost no difference by trying to disconnect from the processes, so an individual can rarely decide to act alone or with just a few other people to change it (2004, p. 387).

The second term (i.e., action) is also central to Young's conclusions about discharging one's social connection responsibility. She writes, "Whereas responsibility as liability assigns responsibility according to what particular agents have done, on the model of political responsibility individuals are responsible precisely for things they themselves have not done." (2004, p. 375 - emphasis in original). This bias toward collective action - and responsibility for inaction further distances SCMR from LMR. Unless some prior commitment demands some positive action (e.g., strict liability, parental responsibility), actors are rarely responsible for inaction according to LMR. Minding one's own business is generally a powerful defense against assertions of responsibility according to the (relatively individualistic) assumptions of LMR.

Shortly after introducing her conceptualization of the SCMR (Young 2003a) business ethics scholars started to apply Young's work to specific business and society-related issues, criticized its usefulness, and attempted to develop it further as discussed in the following section.

\section{Applications and Criticism of SCMR in Business Ethics}

One of the first introductions of Young's work on responsibility to the business ethics literature was made by Scherer et al. (2006) who examined the role of business in global governance and argued that existing concepts were unable to address the on-going global governance deficits. Scherer et al. (2006, p. 514) stress the limitations of the LMR to global governance and draw attention to the need for a more forward-looking approach such as Young's SCMR. This leads them to a call for a "new concept of the firm as a responsible political actor". While the authors 
introduced some of Young's work to the business ethics discourse they only did so briefly without a critical examination. Instead, they stressed the usefulness of Young's broad conceptualizations of political responsibility and need for a forward-looking perspective.

Since then, Young's ideas have surfaced in several contributions to scholarship on political corporate social responsibility (pCSR) (Palazzo and Scherer 2006; Maak 2009; Scherer and Palazzo 2011; Schrempf 2012; Rotter et al. 2014; Wickert 2016). Despite some variation in depth, these contributions generally take Young's ideas and arguments at face value, moving quickly to building out and elaborating their application within specific contexts of interest (global supply chains, financial risk, marketing, etc.).

Though arguably an overestimation of the depth of the conceptual interdependence, Rotter et al. (2014) go as far as to assert that, "responsibility within Political CSR is understood in terms of Young's (2006) model of social connection" (2014, p. 586). Maak (2009) presents a responsibility model for the cosmopolitan corporation that relies on Young's work. He argues that "the obligations of social justice for cosmopolitical corporations arising from their embeddedness in structural social process in the global public sphere are therefore twofold, to create justice by contributing to global social justice and to fight structural injustice as it occurs" (p. 368; italics in original).

Wickert draws on Young's work “...to justify normatively why and to what extent SMEs are confronted with global regulatory gaps" (2016, p. 805). Schrempf (2012) argues that recent CSR issues cannot be explained or addressed by the conventional liability approach to responsibility but instead requires a different approach that grasps the complexity and interrelatedness amongst actions and actors. Wettstein (2012) uses Young's work to present a concept of collaborative responsibility of corporations, which amongst other things is characterized by a collaboration within and across industries, a focus on omission to act, positive duties, and human rights responsibilities. Snyder (2010) examines the ethics of sweatshop labor with a focus on exploitation. He utilizes the SCMR to illustrate the micro and macro level of exploitation and the importance to distinguish the responses to the different types of exploitation.

Schlaile et al. (2018a) and Schlaile et al. (2018a, 2018b) consider the role of consumers in responsible innovation and consumption in light of Young's SCMR. Moggia (2019) argues that existing responsibility models are insufficient to conceptualize the responsibility for systemic financial risk. Instead, he argues that pluralist connection models can overcome the shortcomings of existing responsibility approaches. Moggia concludes that financial institutions have the responsibility for "remedying some of the harms caused by financial crises; supporting the development of better epistemic methods; curbing the transmission and amplification of initial losses; and instigating structural reforms" (2019, p. 1).

Others have sought to extend Young's work by shedding light into how the collective element of Young's SCMR unfolds - more specifically, "which responsibilities concern which groups in society" (Aßländer 2018, p. 1). Aßländer (2018), for example, builds on Young's work and adds the tenet of subsidiarity and Kant's perfect and imperfect duties to provide a clearer conceptualization regarding the different layers of responsibility in society. Schrempf (2014) applies social connection responsibility specifically to obesity, extending Young's concept of responsibility by combining it with network theory to better examine how an actor is connected to a societal problem.

Hahn (2009) bases his concept of 'participatory responsibility' on Young's SCMR. However, he is critical of the model in that "it fails to define a minimal basic-rights threshold and is trapped in the very same problem it originally meant to bypass - 
namely, the problem of the untraceability of causal chains" (Hahn 2009, p. 44). Hahn (2009) provides one of the most detailed critiques of Young's SCMR and the challenges on assigning specific responsibilities. He addresses the challenges raised by introducing a model of participatory responsibility in which an actor's responsibility is related to her contribution to the structures that violate basic rights.

Calder (2010) uses Young's SCMR as a starting point and introduces the principle of unjust enrichment to argue that anyone who benefits from structural injustices has a share in the responsibility to provide restitution to the disadvantaged. Finally, van Buren III et al. (2021) extend Young's model by elaborating on power and the strength of connections and how these factors influence the share of responsibility. More specifically, they provide theoretical depth into Young's conceptualizations on 'social connection' and 'collective ability' when they introduce their pathways to addressing human trafficking.

There are also a few critical reflections on Young's SCMR in the business ethics literature. Like the apologists, these critical passages are generally elaborated by way of juxtaposition with the authors' preferred approach rather than deeply engaging with Young's ideas (e.g., Berkey 2019). Zwolinski (2012) provides a critical account of Young's SCMR in the context of sweatshop labor exploitation. He argues that social injustice "does not typically matter for determining whether a sweatshop is acting exploitatively, and it does not typically matter in a way that grounds any kind of special moral responsibility or fault on the part of sweatshops or the MNEs (multinational enterprises) with which they contract” (2012, p. 155). Addressing Young's arguments directly, Zwolinski writes:

...if what grounds responsibility is not participation in unjust structures as such but wrongful participation in unjust structures, then Young's account would seem to collapse into a standard liability model of responsibility. One might think instead that participation matters because it provides one with opportunities to fight the injustice. But there is no reason to think that all who participate in unjust structures will have such opportunities, nor that all nonparticipants will lack them. It is hard to see, then, how "social connection" could be specified in any way that would nonarbitrarily assign any kind of special responsibility to sweatshops or MNEs for remedying structural injustice. (Zwolinski 2012, p. 174 footnotes removed; see also Powell and Zwolinski 2012, p. 468n106)

Here we see Young's thinking deployed as a foil for the author's preferred account of (non-)responsibility. Specific to our purposes here is the insertion of the word "wrongful". Wrongful participation is a mistaken reading of Young's SCMR. She is explicitly concerned with cases where participation is not wrongful, but nevertheless results in systematic injustice. Recall the "minding their own business" passage quoted above. Indeed, Young (2004) even sees those who are victims of the system as themselves bearing social connection responsibility. With this said, Zwolinski does challenge SCMR to better elaborate the boundary conditions and dynamics of moving between LMR and SCMR. We take this up below.

In summary, SCMR is gaining increasing traction in the business ethics literature. What is missing in these discussions is a systematic internal critique of SCMR specific to the context of business. We hope to strengthen Young's SCMR through friendly, but nevertheless demanding, criticisms of her ideas and their applications with particular attention to questions of business ethics. 


\section{An Internal Critique}

Having laid out the basics of the SCMR, including comparisons to the standard liability models, we can now turn to a deeper consideration of Young's model. In this section, we elaborate on important nuances of SCMR - including:

- Voluntarist

- Process and discourse

- Knowledge, intentional ignorance, and illuminative intention

- Entirely forward-looking

Voluntarist An important distinction between social connection and political obligation is that the latter is based on an affiliation over which one has almost no agency. Social connection responsibilities, on the other hand, are not generated passively (e.g., by birth or residence). Rather, actors bearing SCMR have, in fact, acted within the system under examination. "This obligation is rooted not merely in our being citizens but in our participation as citizens in a political system of social cooperation that facilitates the existence of structural injustices" (Darby and Branscombe 2014, p. 131). This is not to say that working within such a system is a matter of complete free will; only that some plausibly voluntary action is required to generate social connection responsibilities.

The relatively specifiable and voluntary actions leading to these responsibilities are in notable contrast to the outcomes that motivate the need for SCMR. An actor's relative responsibility for harm arising from her participation in an unjust system is difficult to specify - this is why SCMR is necessary. Less difficult to appreciate is the actor's participation in the system itself. And it is this (relatively) voluntary participation that leads to SCR. In other words, while the contribution of an action to systemic injustice is causally ambiguous, the fact of that participation is not.

With this said, the demands we might make based on SCMR also differ. The responsibilities of social connection are not a replacement for laws, punishment, and legal accountability. SCMR supplements these with a (pragmatic) solution-seeking response for those actors who want to address these problems - not from a fear of punishment, but because they are part of a process that is causing harm and most people would prefer to not cause harm to others if avoidable. Recognizing social connection is the first step in the collective action necessary to address structural injustice. Aßländer (2020) summarizes this well writing:

Since most of us bear more responsibility than we can reasonably be expected to discharge we must make choices about our contributions to resolve problems of structural injustices (Young 2006). When referring to power, privilege, interest, and collective ability as guiding principles for making one's choice (Young 2003a, 2003b, Young 2011, pp. 144-147), Young gives some advice how people ought to reason about their individual responsibilities (Hahn 2009) but does not elaborate a rationale for assigning responsibilities. (Aßländer, 2020, p. 723 )

The implication here is that it is the subjects' choice and decision how - and to what degree - to meet their SCRs. Though, in that same paragraph, Aßländer (2020, p. 5) goes on to write, “...we will need a more elaborate conception which would allow for assigning different kinds of responsibilities to different layers in society." We concur that work remains to specify the actions 
recommended by SCMR, but we sound a note of caution where these demands stray from the voluntary. As "recommended" approaches "required", SCMR loses its distinctiveness.

Process and Discourse At various points, Young describes her model as referring to structural "processes". What does it mean to think of structure as a process? Consider this passage:

Accordingly, here I will not attempt to give a sentence or paragraph definition. Instead, I will build an account of social-structural processes whose purpose is only to give some depth to the claim that many judgments of social injustice refer to structural injustice....I shall refer to these aspects of social relations more often as social structural processes than as structures, in order to emphasize the dynamism of action in institutional contexts. (2011, p. 53, emphasis original).

The first thing to notice is that focusing on process and emphasizing dynamism creates a bias for change rather than the inertia of the status quo. As noted above, the possibility of alterations to the socio-cultural structure is a key motivator for the SCMR. If the structure is immutable, efforts to change even unjust structures would be quixotic. However, one of the organizing assumptions of SCMR is the mutability of these social structures/processes. Thinking of SCMR as a process keeps this front of mind.

Young's emphasis on process is, however, among the least developed elements of her final model. This said, the building blocks for further development can be found throughout several of her published works marking the evolution of SCMR. Consider these passages:

Part of what it means to be responsible on the social connection model is to be accountable to others with whom one shares responsibility - accountable for what one has decided to do and for which structural injustices one has chosen to address. When an agent is able to give an account of what she has done, and why, in terms of shared responsibilities for structural injustice, then others usually ought to accept her decision and the way she sets priorities for her actions. (Young 2006, p.126).

Sharing responsibility means, in part, that agents challenge one another and call one another to account for what they are doing or not doing. (Young 2006, p. 130)

The form of responsibility, then, is political in these senses that acting on my responsibilities involves joining with others in a public discourse where we try to persuade one another about courses of collective action that will contribute to ameliorating the problem (Young 2004, p. 380 emphasis added).

Taken together - alongside the emphasis on process - these passages point to a role for discourse ethics as a (perhaps the) outcome of interest for SCMR. Though the connections and their implications await more explicit and detailed elaboration, scholarly interest in Habermas's discourse ethics and Young's SCMR evidence scholarly affinity (or, at least, cognitive cohabitation if measured by the number of scholars writing on both; cf. Scherer, et al., (2006), Wettstein (2010), Schrempf-Stirling and Palazzo (2016)).

Young also provides some candidate parameters for governing SCMR discourse derived from the motivating distinction between SCMR and LMR. She writes,

Frequently the reaction of people being blamed for a wrong is defensive - to look for other agents who should be blamed instead of them, or to find excuses that mitigate their 
liability in those cases where they must agree that their actions do causally contribute to the harm. Such practices of accusation and defense have an important place in morality and law. In many contexts where the issue is how to mobilize collective action for the sake of social change and greater justice, however, such rhetorics of blame and fingerpointing displacement lead more to resentment and refusal to take responsibility than to useful basis of action. (2004, p. 381)

Future research might fruitfully consider what other ground rules apply to discourses distinctive to SCMR.

Knowledge, Intentional Ignorance, and Illuminative Intention Knowledge of both actions and likely consequences is vital LMR. Indeed, ignorance is a standard, if fraught, element of assigning responsibility. Barring something like strict liability, ignorance is often taken to mitigate responsibility. If a manager or product endorser is unaware of the working conditions under which a supplier's supplier's employees labor, many would argue that the manager is not responsible.

Whereas a strict responsibility to know and understand the plight of everyone suffering from structural injustice would demand too much (and likely risk shifting from SCMR to LMR), SCMR can render judgement on intentional ignorance. If a manager intentionally adds links to a value chain to avoid responsibility, such artificially imposed ignorance catalyzes structural injustice. Sub-sub-sub-contracting relationships, Russian doll articles of incorporation, and shell game holding companies are only a few of the structural innovations that have facilitated systemic injustice. Any model of responsibility that permits or encourages this sort of manufactured deniability is itself an irresponsible model.

More nuanced and relevant for SCMR are instances of honest ignorance. Cases of honest ignorance are certain to emerge and re-emerge. Ever increasing complexity, innovation, and global interconnectedness make the growth of such honest ignorance a near certainty. Seemingly innocuous when compared to intentional harm, thoughtlessness is among the chief sources of structural injustice. Young mentions this prospect in her "partial" critique of Arendt's work on collective responsibility:

On Arendt's account, Eichmann's main character failing was not that he was cruel, malevolent, self-serving, or stupid, but that he was thoughtless. He failed to think about the meaning of his actions and their consequences, failed to understand the bureaucratic system from the point of view of its victims, failed to reflect upon the wider meaning of the social and political system in which he participated. (Young 2011, p. 84).

SCMR requires an illuminative intention. Openness to seeing and understanding sources of structural injustice and its amelioration is a central responsibility for SCMR. Once these sources have been identified, each actor bears an additional responsibility for discursive accountability.

Entirely Forward Looking As discussed above, one differentiating feature between SCMR and LMR is that SCMR is "more" forward-looking. We want to defend the proposition that Young's distinction does not go quite far enough in this regard. We should replace the qualifier "more-" with "entirely" forward looking. In one of her most stirring phrases, Young writes, 'One has the responsibility always now..." (2011, p. 92 - emphasis original). Is a theory of the "always now" viable? Is it coherent, or even possible, to bracket the past entirely when assessing responsibility - and the actions demanded by this assessment? 
Here it is important to recall that responsibilities under SCMR are distinct from - and supplementary to - other forms of responsibility (more on this relationship below). Just as guilt, blame, punishment, and restitution have no positive vision for reducing structural injustice, so too must SCMR stand silent on questions of blame, guilt, punishment and restitution.

There are, however, two vital uses for knowledge of the past to SCMR: diagnostic and prognostic. As Young writes,

There is an important sense, then, however, in which political responsibility must be backward looking. An understanding of how structural processes produce and reproduce requires understanding the history of those processes, often looking far into the past. The purpose of this analysis of past events is not to find perpetrators, however, but rather to understand how actions and policies have long term effects and how the effects can solidify into structures that conditions [sic] new actions. (Young 2003a, p. 13)

This is the diagnostic purpose of the past - how things got to be this way. To this we would add the prognostic use. Though necessarily contestable (Schrempf-Stirling, Palazzo, and Phillips 2016t . 2012), the past is a key source of evidence for what actions/programs/policies/etc. are more or less likely to work going forward (Phillips et al. 2020). Among the most pragmatically relevant elements of SCMR is its focus on learning and solutions. Looking forward involves the imaginative consideration of alternative actions, processes, and mechanisms. Consideration of alternatives necessarily involves examination of the likely outcomes of a given choice. The data informing this evaluation must, of course, come from relevant prior experiences. In short, we look to the past to predict the most likely forward-looking outcomes of the choices faced.

Notably, Nussbaum's own response to the above criticism is the potential loss of a learning opportunity. She writes, 'If we just say to people, 'From now on conserve energy,' without showing in detail how the wasteful lifestyle of Americans contributes to global harms, little learning takes place, and moral incentives are not created. By contrast, when we say, 'Look at how large your carbon footprint is,' learning is promoted and motivation is strengthened by a confrontation with one's own obviously quite harmful acts." (Nussbaum 2011, p. xxiii). This seems to assume that learning and motivation are enhanced by blame, guilt, or some other missing element of the backward-looking liability approach. The motivational qualities of guilt may play a role (cf., Nussbaum, p. xxiv), but for the cases most relevant to SCMR, no particular actor's guilt rises to the level of blameworthiness. This is what gives rise to the need for a new way of thinking about responsibility.

Maintaining exclusive focus on the future is among the most challenging aspects of SCMR. The language of causality, blame, guilt, punishment, and restitution are deeply embedded in our understanding of responsibility. It is similarly difficult to maintain contact with the idea that SCMR is always on-going. Quoting Young, "The injustices produced through structures have not reached a terminus, but rather are ongoing. The point is not to compensate for the past, but for all who contribute to processes producing unjust outcomes to work to transform those processes" (2011, p. 108).

SCMR perseveres as long one participates in a system producing significant injustice even when these effects are unintended. This persistent forward-looking perspective means that neither blame nor redress can be apportioned as would be required of the liability approaches. Because the injustice is on-going, the tally grows. Even if we were able identify the causal actors and the relative apportionment of their blame, we would still lack the proper denominating total harm over which to allocate redress. The sediment of history and harm accumulates in perpetuity. 


\section{LMR and SCMR: Division of Conceptual Labor}

As evidenced above, concepts like blame, accountability, and compensation are difficult to shake when discussing responsibility. Reading the received literature on responsibility, one could be excused for believing it impossible to discuss responsibility without including some explanation for blame, guilt, and restitution. This creates a severe obstacle for LMR in contexts where responsibility is diffused among a myriad of actors, none of whom has done anything outside the norms and expectations of that context.

Young's resolution to this obstacle is to establish a division of labor between SCMR and liability approaches to responsibility. She writes, “...structural injustice is a special kind of responsibility, rather than a variation on responsibility understood as guilt, blame, fault, or liability" (2011, p. 97). Further, Young does not see SCMR as supplanting liability approaches claiming rather, "I do not aim to replace or reject the liability model. I am claiming instead that the liability model is appropriate in some contexts but not all" (2011, p. 100). Young continues, "At the point when we consider issues of responsibility in relation to structural injustice, quantitative difference becomes qualitative difference. What we should seek is not a variation on a weaker form of liability, but rather a different conception of responsibility altogether" (2011, p. 104).

Critics of SCMR have, at times, failed to recognize this division of labor. Whether attempting to assimilate SCMR into legacy conceptions (or their own novel theoretical variation) or merely taking pot shots at the model, critics often plow through this tension without a second thought. For example, Hahn writes, "Power, privilege, interest and insight play a role, but the pre-eminent factor is, in my opinion, the seriousness of the respective wrong" (2009, p. 51). Does the seriousness of the wrong not also cross the boundary into LMR? As alluded in our discussion of voluntarism, if the wrong is serious enough to compel action, it is already a candidate for treatment under liability conceptions of responsibility.

Just how distinctive the variants are, and how one may morph or transition into the other remains undertheorized ${ }^{4}$ and the contours of this boundary are underspecified. Relatedly, it is also important to account for movement between the models. For any given occurrence of structural injustice, how are we to know which model is most appropriate to inform our understanding of responsibility?

We see at least three possible conceptualizations of the relationship between the SCMR and LMR: independent, embedded, and overlapping.

Independent Conceptual independence holds if our models of responsibility are determined to be incompatible with each other - where the one applies, the other one cannot. The two models are logically and theoretically distinct. While it is true that the two responsibility

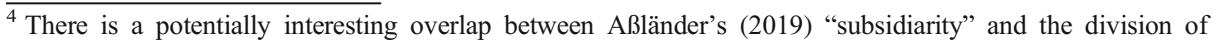
conceptual labor defended here. He writes, "The tenet of subsidiarity states that in a society no task should be assigned to a higher level of authority if it can be accomplished by a lesser and subordinate entity." Aßländer argues for three "layers" in society and that the broadest of these (e.g., national governments) should only intervene to support where more narrow levels (e.g., individuals and organizations) cannot. There is a potential symmetry between Aßländer's layers and the argument presented here. That is, we might be able to say that group responsibility should start with considerations of SCMR. Recognition of these relatively voluntarist responsibilities may prove inadequate, for example, when the injustice becomes so drastic that a more organized (higher level) response is needed. This may mean recourse to organization-level responsibilities (e.g., obligations of fairness) or legislative and regulatory interventions. Importantly, recourse to one of these broader levels does not relieve the actors of the lower-level responsibilities.
} 
models are conceptually distinct, it does not necessarily mean there is no common ground or interaction between them. A distinction is not the same as a dichotomy (Putnam 2004). Young developed SCMR precisely because LMR has been unable to adequately address certain prevalent and important modern conditions.

Embedded This conceptualization of the relationship between the two models envisions LMR to be embedded in SCMR. With SCMR taking a systemic perspective - constantly questioning and re-evaluating the underlying structures their implications on individual actions and their consequences - it is plausible to conceive of SCMR as entirely encompassing LMR. SCMR starts, in a sense, 'prior to' LMR in that it questions the underlying structures and norms. SCMR takes a broad perspective and goes to the sources of injustices, beyond individual wrongdoing to the deeper questions of structural conditions that led to the wrongdoing. SCMR takes systemic perspective that the LMR does not. When we think of moving a discussion "up a level" the image is that of drawing back from the finer points to gain a better view of the larger context.

Overlapping On this conceptualization, SCMR and LMR overlap, i.e. there are situations where both are applied and needed. This joint application can be either simultaneously (in parallel) or in sequence (one after the other). This understanding depicts some distinctiveness and maybe even rivalry between the two, but likewise it suggests a form of collaboration. Where the two depend on each other or where issues cannot be solved by one alone. So, there is a sort of conceptual interdependence.

One way of assessing this relationship is to consider the dynamics of organizing a response to structural injustice. Recall that among Young's four key features of SCMR is that the responsibilities are "discharged only through collective action." Elaborating, Young writes:

On the social connection model, workers share responsibility for combating sweatshop conditions and ought to be organized in order to do so (Young 2006, p. 124 - emphasis added).

...institutions are a necessary means for promoting justice, if indeed social justice concerns broad patterns of social positions and relationships in the society. For the promotion of justice requires collective action, and that requires organization (Young 2011, p. 69 - emphasis Young's).

This is perhaps where we are most critical of Young's groundbreaking work. Her insistence that SCMR responsibilities can only be discharged through collective action presents a minor paradox. The process of organizing creates a collective agent capable of intentions, decisionmaking capacities, and expectations. But in light of these intentions, capacities, and expectations, this newly organized collective agent now bears liability model responsibilities. Where responsibilities are specifically assigned, something closer to strict liability is created. This process of organization is the boundary case for a dynamic relationship between SCMR and LMR. Discharging SCMR can be only loosely organized at most lest it veer into confound with the LMR against which it is juxtaposed.

We conclude, therefore, that SCMR co-exists - and dynamically overlaps with - other conceptions of responsibility. The lines distinguishing SCMR and LMR are not bright ones and dynamic normative environments will manifest contested cases. SCMR can develop into LMR, for example, where organization increases capacities and expectations, where new legislation is introduced, or where the magnitude of harm demands more specific and compulsory redress. 
There are also cases where LMR becomes better analyzed as SCMR. Increasing structural complexity, for example, may give rise to a more fine-grained analysis rendering parts of system - previously considered a unified subject of LMR - partially subject to SCMR. Demands to withdraw entirely from doing business in countries with troubling human rights regimes (divestment) have yielded to more nuanced conversations about what elements of that regime a company might reasonably influence. Companies may have liability for how their direct stakeholders are treated, but social connection responsibility to the non-stakeholder members of that society. There is liability responsibility where child labor is directly implicated in a supply chain, but social connection responsibility for child labor in the country outside this direct relationship.

Human rights considerations such as these were of utmost concern to Young and have been the focus of many business ethics scholars employing her work. We turn now to a brief discussion on business and human rights to illustrate the relevance and limits of SCMR for business ethics.

\section{The Case of Business \& Human Rights and SCMR}

Business and human rights (BHR) performs a bridging role between LMR and SCMR (cf., Hahn 2009). BHR is the context and frame for the sources of autonomy, well-being, and selfesteem that some believe should be codified (LMR), but are not yet institutionally sanctionable (perhaps due to on-going disagreement about the severity or prominence of the injustice, jurisdiction, practicability, power, etc.). As such, BHR provides an important arena for the contest over organized enforcement and the line(s) between LMR and SCMR.

Broadly speaking, BHR scholarship examines corporate responsibility and accountability for various forms of direct and indirect involvements of business in human rights violations along corporate value chains (Bernaz 2017; Santoro 2015). BHR grew out of a discussion by legal scholars and human rights advocates with an emphasis on the notion of (moral) rights and remedy (Ramasastry 2015). Human rights are moral rights that "exist prior to, or independently of, any legal or institutional rules" (Feinberg 1973: 84). Thus, these rights exist prior to any artificial structures and processes (cf. Nussbaum 2002; Pascal 2020).

This pre-legal origin notwithstanding, the recent surge in discussions of human rights specifically in the context of business - looks to national and international law for solutions. BHR often concludes with calls for legal enforcement and redress and bears a strong backward-looking orientation. It seeks to identify rights violations and perpetrators and to provide remedy to victims of human rights violations. This legalistic emphasis leads to difficulties in applying SCMR to BHR. At the same time, BHR bears exactly the features motivating the need for a new way of thinking about responsibility. BHR demands changes to structures and processes and requires shared efforts to eradicate human rights violations. The BHR debate incorporates elements of both perspectives of responsibility. It started out with a quest for remedy, blameshifting, isolating perpetrators (classic LMR) but more recently incorporates elements of SCMR.

A good illustration is the development of the United Nations Guiding Principles on Business and Human Rights that started in 2005 with the first mandate of Harvard professor John Ruggie who during his 6-year mandate talked to a plethora of stakeholders, from human rights victims, civil society organizations, multilateral organizations, businesses, and governments to explore the complexity of business' connection to human rights violations. The result of his mandate, the UN 
Guiding Principles on Business and Human Rights (GPs) have been unanimously adopted by the UN Human Rights Council- the first of its kind to be endorsed by the UN.

The GPs outline the state's duty to protect its citizens from human rights violations (including those committed and abetted by business), the business responsibility to respect human rights, and the shared responsibility of states and businesses to provide access to remedy for the victims of human rights violations (Ruggie 2011). Nolan (2013, p. 140) describes the GPs as the "latest in a long line of soft regulatory techniques used to encourage, but not require, a corporation to comply with human rights." The GPs have initiated actions by a variety of stakeholders: Companies started to use the GPs in their supply chain due diligence programs, and states started creating national action plans (NAPs) - an "evolving policy strategy developed by a State to protect against adverse human rights impacts by business enterprises in conformity with the UN Guiding Principles on Business and Human Rights" (UNWG 2016, p. 3). NAPs should assess a country's current state of human rights protection and, based on it, outline areas in need of further policy action on the part of the government (Cantú Rivera 2019). At the same time, we observe how victims and civil society organizations use legal instruments available to them such as the French Vigilance Law to obtain remedy for human rights violations. These quests for justice include classic elements of LMR, such as blaming business for occurred harm, absolving other actors, and looking backwards.

At the same time, when we look deeper into the evolution of BHR we find scholars moving away from LMR towards more SCMR. This is most prominent in the BHR scholarship that focuses on the normative argumentation of why business have human rights obligations (Schrempf-Stirling and van Buren 2020). Scholars apply Kantian ethics (Luke 1998; Hahn 2009), Confucian ethics (Kim 2014) or social contract theory (Cragg 2000; Bishop 2008). These elaborations on the responsibility of business for human rights are not about blame but dominated by a quest to anchor business responsibility for human rights in a voluntarist, institutionally neutral zone with an emphasis on the future. This is exemplified in Wettstein's (2012, p. 158) call for "a new perspective on morality, one that is better able to cope with the new challenges of our 'collective age'."

The current BHR debate, as such, incorporates elements of both LMR and SCMR. On the one hand, legal scholars discuss how we can hold business accountable and define clear structures and a baseline (background conditions) that help determine when individuals/ firms deviate from it and can be blamed and punished. At the same time, there is the understanding that human rights abuses are structural injustices that require collective action and a transformation of social structures, processes, and institutions linked to the fulfilment of positive duties. This is a living example of the division of conceptual labor between the two concepts of responsibility and the on-going contest about the contours of this division.

In sum, we offer two caveats to those seeking to apply SCMR to BHR. First, the conditions for invoking SCMR may structurally co-exist with human rights violations by businesses, but if companies are directly violating human rights, then failing to meet their social connection responsibilities is a secondary consideration (cf., Phillips, 2003). Additionally, because SCMR is exclusively forward looking, it must stand mute on reconciliation concerns. This creates a potential gap in its application to BHR.

\section{Concluding Remarks}

In this article, we critically reflected on social connection responsibility, explored its relationship to the standard model of assigning responsibility (liability model of responsibility), and 
illustrated the relevance and limits of social connection responsibility by applying it to the emerging scholarship on business and human rights. Nevertheless, open issues remain.

Among the sticky questions left unanswered is what sort of responsibility applies to individual managers wishing to use their position within an organization to meet their SCMR responsibilities. Among Young's "parameters of reasoning about responsibility" is "collective ability." (Too) briefly elaborating on this important set of ideas, she writes, "Some agents are in positions where they can draw on the resources of already organized entities, and use them in new ways for trying to promote change. Unions, church groups, and stockholder organizations, to name just a few, sometimes can exercise significant power not because they can coerce others to do what they decide, but because they have many members who act together" (Young 2011, p. 147). This needs much closer attention as one source of better understanding actors' LMR and SCMR responsibilities.

Another lingering difficulty for SCMR involves the precise contours of its applicability. SCMR is intentionally defended as but one source of responsibility - a source with a specific application. However, as with similarly delimited moral principles, the range of applicability is a source of both strength and critique. Consider, for example, Phillips's principle of stakeholder fairness. Phillips argues that the principle of stakeholder fairness is only directly applicable in cases where a voluntary obligation-generating action (e.g., consent or contracting) is undertaken (Phillips, 2003). This principle is explicitly not intended as a comprehensive theory of moral and political obligation. But determining exactly where it resides along the spectrum of applicability remains subject to contest.

What is the relationship between SCMR and supererogation (e.g., Dmytriyev 2019; Tencati et al. 2020)? Hahn asserts that, “...the social connection model...refines and thereby shifts the difference between responsibilities for justice and supererogative deeds" (2009, p. 55n31). The intuitive overlap between supererogation and social connection responsibilities suggest that there may be insight in relating the two literatures.

To conclude, Young has provided us with a fruitful alternative perspective on responsibility that has sparked lively discussions amongst business ethicists. The theory's progenitor herself believed SCMR to be incomplete. The intention underlying our appraisal and internal critique of SCMR is to encourage its continued development of SCMR in business ethics. Like structural injustices, the demands of SCMR may never reach a terminus, but there is value in contesting its contours and asking what we may demand of ourselves and others. However long we may suppose the arc of the moral universe, for us it is always now... and the arc does not bend itself.

Acknowledgements The authors wish to thank Heather Elms, Kendy Hess, and Florian Wettstein for helpful conversations.

Open Access This article is licensed under a Creative Commons Attribution 4.0 International License, which permits use, sharing, adaptation, distribution and reproduction in any medium or format, as long as you give appropriate credit to the original author(s) and the source, provide a link to the Creative Commons licence, and indicate if changes were made. The images or other third party material in this article are included in the article's Creative Commons licence, unless indicated otherwise in a credit line to the material. If material is not included in the article's Creative Commons licence and your intended use is not permitted by statutory regulation or exceeds the permitted use, you will need to obtain permission directly from the copyright holder. To view a copy of this licence, visit http://creativecommons.org/licenses/by/4.0/.

\section{References}

Appiah, K.A. 2008. Experiments in ethics. Harvard University Press. 
Aßländer, M. S. (2018). How to overcome structural injustice? Social connectedness and the tenet of subsidiarity. Journal of Business Ethics, 1-14.

Berkey, B. (2019). Sweatshops, structural injustice, and the wrong of exploitation: Why multinational corporations have positive duties to the global poor. Journal of Business Ethics, 1-14.

Bernaz, N. 2017. Business and human rights: History, law and policy-bridging the accountability gap. Routledge.

Bishop, J.D. 2008. For-profit corporations in a just society: A social contract argument concerning the rights and responsibilities of corporations. Business Ethics Quarterly 18 (2): 191-212.

Calder, T. 2010. Shared responsibility, global structural injustice, and restitution. Social Theory and Practice 36 (2): 263-290.

Cantú Rivera, H. 2019. National action plans on business and human rights: Progress or mirage? Business and Human Rights Journal 4 (2): 213-237.

Cragg, W. 2000. Human rights and business ethics: Fashioning a new social contract. Journal of Business Ethics 27 (1): 205-214.

Darby, D., and N.R. Branscombe. 2014. Beyond the sins of the fathers: Responsibility for inequality. Midwest Studies in Philosophy 38 (1): 121-137.

Dmytriyev, S. (2019). Supererogation in organizations: Going beyond duty in a morally praiseworthy way. Unpublished dissertation, Darden Graduate School of Business, University of Virginia.

Feinberg, J. 1973. Social philosophy. Englewood Cliffs: Prentice Hall.

Fletcher, G. 1999. Basic concepts of criminal law. Oxford: Oxford University Press.

Greene, J.D. 2013. Moral tribes: Emotion, reason, and the gap between us and them. Penguin.

Hahn, H. 2009. The global consequence of participatory responsibility. Journal of Global Ethics 5 (1): 43-56.

Hess, K.M. 2014. Because they can: The basis for the moral obligations of (certain) collectives. Midwest Studies in Philosophy 38 (1): 203-221.

Kim, T.W. 2014. Confucian ethics and labor rights. Business Ethics Quarterly 24 (4): 565-594.

Luke, T. 1998. The ethics of using trade policy to evoke change: The China-US example. Business Ethics: A European Review 7 (4): 231-234.

Maak, T. 2009. The cosmopolitical corporation. Journal of Business Ethics 84 (3): 361.

May, L. 1992. Sharing responsibility. Chicago: University of Chicago Press.

Moggia, J. (2019). Moral responsibility for systemic financial risk. Journal of Business Ethics, 1-13.

Nolan, J. 2013. The corporate responsibility to respect human rights: Soft law or not law? In Human rights obligations of business: Beyond the corporate responsibility to respect? ed. S. Deva and D. Bilchitz, 138161. Cambridge: Cambridge University Press.

Nussbaum, M.C. 2002. Capabilities and human rights. In Global justice and transnational politics: Essays on the moral and political challenges of globalization, ed. P. De Greiffand C. Cronin, 117-149. Cambridge: The MIT Press.

Nussbaum, M. 2011. Foreword. In Responsibility for justice, ed. I.M. Young, ix-xxv. New York: Oxford University Press.

Palazzo, G., and A.G. Scherer. 2006. Corporate legitimacy as deliberation: A communicative framework. Journal of Business Ethics 66 (1): 71-88.

Pascal, AM. (2020). Business and human rights, from theory to practice and law to morality: Taking a philosophical look at the proposed UN treaty. Philosophy of Management, online first, 1-34.

Phillips, R. 2010. Ethics and network organizations. Business Ethics Quarterly 20 (3): 533-544.

Powell, B., and M. Zwolinski. 2012. The ethical and economic case against sweatshop labor: A critical assessment. Journal of Business Ethics 107 (4): 449-472.

Putnam, H. 2004. The collapse of the fact/value dichotomy. Cambridge: Harvard University Press.

R.A. Phillips, (2003) Stakeholder Theory and Organizational Ethics, (San Francisco: Berrett-Koehler Publishers).

R. Phillips, J. Schrempf-Stirling, C. Stutz, (2020) "The Past, History, and Corporate Social Responsibility," Journal of Business Ethics. 166 (Oct), 203-213.

Ramasastry, A. 2015. Corporate social responsibility versus business and human rights: Bridging the gap between responsibility and accountability. Journal of Human Rights 14 (2): 237-259.

Rotter, J.P., P.E. Airike, and C. Mark-Herbert. 2014. Exploring political corporate social responsibility in global supply chains. Journal of Business Ethics 125 (4): 581-599.

Ruggie, J. (2011). Guiding principles on business and human rights: Implementing the United Nations "protect, respect and remedy" framework. Report of the Special Representative of the Secretary-General on the Issue of Human Rights and Transnational Corporations and Other Business Enterprises, available at: https:// www.ohchr.org/documents/publications/guidingprinciplesbusinesshr_en.pdf. Accessed 4 Dec 2020.

Santoro, M.A. 2015. Business and human rights in historical perspective. Journal of Human Rights 14 (2): $155-161$. 
Scherer, A.G., and G. Palazzo. 2011. The new political role of business in a globalized world: A review of a new perspective on CSR and its implications for the firm, governance, and democracy. Journal of Management Studies 48 (4): 899-931.

Scherer, A.G., G. Palazzo, and D. Baumann. 2006. Global rules and private actors: Toward a new role of the transnational corporation in global governance. Business Ethics Quarterly 16 (4): 505-532.

Schlaile, M.P., K. Klein, and W. Böck. 2018a. From bounded morality to consumer social responsibility: A transdisciplinary approach to socially responsible consumption and its obstacles. Journal of Business Ethics 149 (3): 561-588.

Schlaile, M.P., M. Mueller, M. Schramm, and M. Pika. 2018b. Evolutionary economics, responsible innovation and demand: Making a case for the role of consumers. Philosophy of Management 17: 7-39.

Schrempf, J. 2012. The delimitation of corporate social responsibility: Upstream, downstream, and historic CSR. Business \& Society 51 (4): 690-707.

Schrempf, J. 2014. A social connection approach to corporate responsibility: The case of the fast-food industry and obesity. Business \& Society 53 (2): 300-332.

J. Schrempf-Stirling, G. Palazzo \& R.A. Phillips, (2016) "Historic Corporate Social Responsibility," Academy of Management Review, 41(4), pp. 700-19.

Schrempf-Stirling, J., and G. Palazzo. 2016. Upstream corporate social responsibility: The evolution from contract responsibility to full producer responsibility. Business \& Society 55 (4): 491-527.

Schrempf-Stirling, J., and H.J. van Buren. 2020. Business and human rights scholarship in social issues in management: An analytical review. Business and Human Rights Journal 5 (1): 28-55.

Schrempf-Stirling, J., G. Palazzo, and R.A. Phillips. 2012. Ever expanding responsibilities: Upstream and downstream corporate social responsibility. In Sustainable value chain management: Analyzing, designing, implementing, and monitoring for social and environmental responsibility, ed. A. Lindgreen, F. Maon, J. Vanhamme, and S. Sen, 353-368. Farnham: Ashgate.

Snyder, J. 2010. Exploitation and sweatshop labor: Perspectives and issues. Business Ethics Quarterly 20 (2): 187-213.

Tencati, A., N. Misani, and S. Castaldo. 2020. A qualified account of supererogation: Toward a better conceptualization of corporate social responsibility. Business Ethics Quarterly 30 (2): 250-272.

UNWG. 2016. Guidance on national action plans on business and human rights. Geneva: UN Working Group on Business and Human Rights.

Van Buren III, H. J., Schrempf-Stirling, J., \& Westermann-Behaylo, M. (2021). Business and human trafficking: A social connection and political responsibility model. Business \& Society, 60(2), 341-375.

Wettstein, F. 2010. The duty to protect: Corporate complicity, political responsibility, and human rights advocacy. Journal of Business Ethics 96 (1): 33-47.

Wettstein, F. 2012. Corporate responsibility in the collective age: Toward a conception of collaborative responsibility. Business and Society Review 117 (2): 155-184.

Wickert, C. 2016. "Political" corporate social responsibility in small-and medium-sized enterprises: A conceptual framework. Business \& Society 55 (6): 792-824.

Young, I. M. 2003a. Political responsibility and structural injustice. In: The Lindley Lecture. Lawrence: University of Kansas. https://kuscholarworks.ku.edu/bitstream/handle/1808/12416/ politicalresponsibilityandstructuralinjustice-2003.pdf?sequence=1. Accessed 4 Dec 2020.

Young, I.M. 2003b. From guilt to solidarity: Sweatshops and political responsibility. Dissent 50 (2): $39-44$.

Young, I.M. 2004. Responsibility and global labor justice. The Journal of Political Philosophy 12 (4): 365-388.

Young, I.M. 2006. Responsibility and global justice: A social connection model. Social Philosophy and Policy 23 (1): 102-130.

Young, I.M. 2011. Responsibility for justice. New York: Oxford University Press.

Zwolinski, M. 2012. Structural exploitation. Social Philosophy and Policy 29 (1): 154-179.

Publisher's Note Springer Nature remains neutral with regard to jurisdictional claims in published maps and institutional affiliations.

Robert Phillips is George R. Gardiner Professor in Business Ethics and Professor of Strategic Management at the York University's Schulich School of Business. His PhD is from the University of Virginia's Darden School. His work has appeared in Business Ethics Quarterly, Strategic Management Journal, and the Academy of Management Review among others. He is author of Stakeholder Theory and Organizational Ethics (2003). His other research interests include, stakeholder theory, historic corporate responsibility, and ethics in network organizations. 
Judith Schrempf-Stirling is associate professor of responsible management at the University of Geneva, Geneva School of Economics and Management. Her PhD is from the University of Lausanne. Her research interests focus on historic corporate social responsibility, business and human rights, and responsible consumption. Her articles have appeared in such journals as Academy of Management Review, Business and Society, Business and Human Rights Journal, Business Horizons, and Journal of Business Ethics. 